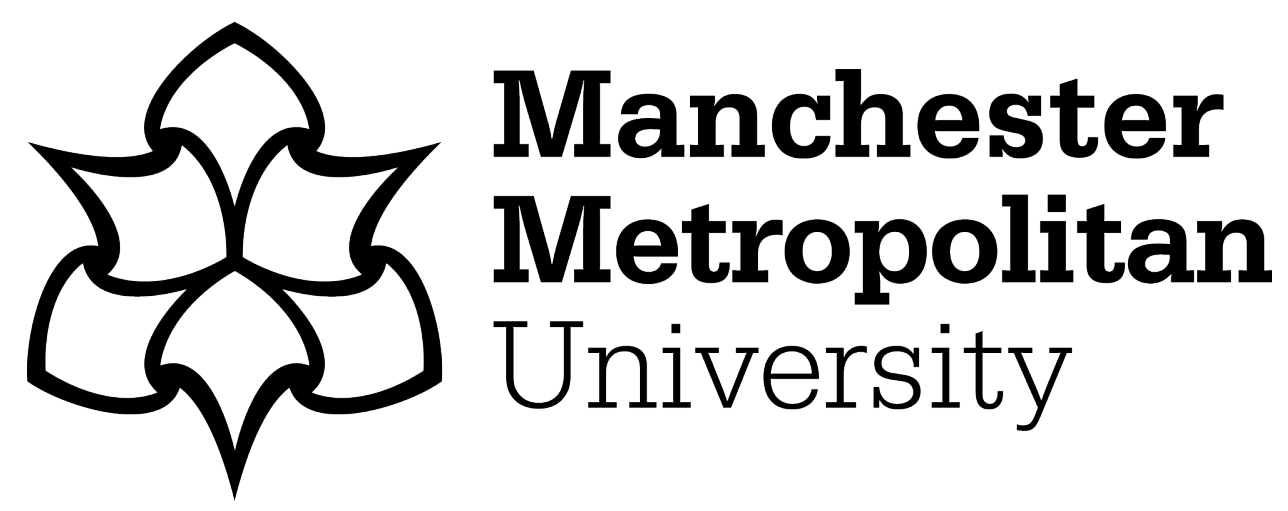

Rhoden, S ORCID logoORCID: https://orcid.org/0000-0002-6509-7347 and Kaaristo, M ORCID logoORCID: https://orcid.org/0000-0002-2803-0418 (2020) Mobile landscapes and transport tourism: the visual experience of mobility during cruises and coach tours. International Journal of Culture, Tourism, and Hospitality Research, 14 (3). ISSN 1750-6182

Downloaded from: https://e-space.mmu.ac.uk/626392/

Version: Accepted Version

Publisher: Emerald

DOI: https://doi.org/10.1108/IJCTHR-01-2020-0036

Please cite the published version 
Please cite the final published version of this paper as follows: Rhoden, S. \& Kaaristo, M. (2020).

Mobile landscapes and transport tourism: the visual experience of mobility during cruises and coach tours. International Journal of Culture, Tourism and Hospitality Research, 14(3), pp. 307-319.

\title{
Mobile landscapes and transport tourism: The visual experience of mobility during cruises and coach tours
}

\author{
Steven Rhoden and Maarja Kaaristo \\ Department of Marketing, Retail and Tourism, Manchester Metropolitan University \\ s.rhoden@mmu.ac.uk,m.kaaristo@mmu.ac.uk
}

Purpose: This study analyses the visual aspects of transport tourists' experience of mobility focusing on British cruise and coach tourists' international travel experiences.

Design/methodology/approach: The qualitative data were collected using semi-structured in-depth interviews with coach and cruise tourists and analysed using thematic analysis.

Findings: The visual experience of mobility (demonstrated in the paper by the example of cruises and coach tours) is critical in the formation of transport tourism experiences. The mobile tourist landscapes emerge from the interplay of the subjective experiences of particular modes of mobility (vehicle or vessel) and routes, whereby the two key visual elements are the changing scenery and views of everyday local life as experienced whilst travelling.

Research limitations/implications: The present study focuses particularly on the visual elements of 'passive' transport tourism experiences. It does not account for other tourist activities nor does it study the experiences associated with active transport tourism. Future research could perform a holistic analysis of tourists' experiences of transport in all its forms.

Practical implications: The findings point to the centrality of the experience of mobility in transport tourism experience. The following two key aspects of the experience emerged: the importance of variation of the scenery that the tourist consume during their tour and a desire to observe mundane, everyday life elements of the destination, which should be taken into account by the tour operators and service providers in the route design and marketing.

Originality/value: Coach and cruise tourism are rarely analysed together; this study demonstrates considerable parallels between the two in considering them as transport tourism, a mode of recreational activity where mobility is the central part of the tourist experience and should therefore be considered a tourist attraction in and of itself.

Keywords: transport tourism, tourist experience, visual experience, mobilities, cruise, coach, landscape 


\section{Introduction}

The tourist experience is a well-established subject of much research interest within tourism studies and the theoretical, methodological and empirical approaches to this subject are rich and varied. The dominant focus of study has largely been on tourist satisfaction, practices, motivations and performances at the various destinations (e.g. Quan and Wang, 2004; Ryan, 2010; Volo, 2013; Ellis et al., 2017; Dodds, 2019). This is of course unsurprising, given that tourists go on holiday to specific destinations - yet it is but one part of the broader tourist experience. In addition to the activities at the destinations, there are also pre-, and post-travel experiences (Sharples, 2019), which include transport to and from the destination and within it (Hall, 1999; Dickinson and Robbins, 2008; Smith et al., 2019). However, it is important to acknowledge that transport is not only a utilitarian travel component comprised of monetary price, time, distance and the (in)convenience of travel (Metz, 2004), it can also be an integral or even central part of the tourist experience or an attraction in its own right. This 'transport as tourism' (Lumsdon, 2000: 364) means seeking out movement purposefully as an enjoyable activity and experience in its own right on a wide variety of motorised and non-motorised vehicles, vessels and aircraft (Ory and Mokhtarian, 2005; Diana, 2008).

The present paper will accordingly focus on two modes of transport as tourism: maritime cruises and coach tours. They will be conceptualised in this paper as 'passive' transport tourism, those in which the tourist has no active role in steering nor navigational planning for the transportation mode whilst it is in motion. Although research on one product type very rarely refers to the other, considerable parallels become evident between them when paying attention to mobility as a tourism attraction. Both coach trips and cruises are examples of standardised mass 'tourist bubbles' (Jaakson, 2004) and can be viewed as safe-havens for tourists travelling through unfamiliar landscapes. Cruise ships have for all intents and purposes become destinations in their own right (Di Vaio et al., 2018) and coaches represent safe, almost insulated environments for tourists to travel through, and visually consume, unfamiliar landscapes (Tucker, 2007). Both of these are particular mobile - ways of engaging with the surrounding environment, one in which transport 'is not only a trivial question of overcoming distance and reaching, it is a way of being in, and experiencing various landscapes' (Larsen, 2001: 81). 
This paper will explore transport as a tourist experience, focusing on the role of mobility, socio-culturally meaningful movement (Sheller and Urry, 2004; 2006; Edensor, 2007; Hannam, 2009), in the co-production of the visual experience of the travelling landscapes. The paper is structured as follows: first, we will review the extant literature on transport tourism mobilities and the visual experience of tourism landscapes. After an overview of the qualitative data collection and analysis methods, we will present the results of the study, identifying the two key elements that determine the visual tourist consumption of mobility: variability of the scenery and the everyday life. Finally, we highlight the paper's limitations and implications for further research and application to practice.

\section{Transport tourism as mobile attraction}

'Transport is a fundamental requirement for tourism to occur' (Page and Connell, 2014: 155) and while the two intersect profoundly, two main purposes can be identified, even though they are best conceptualised as ends of a continuum rather than discrete categories. First, 'transport for tourism' (Lumsdon and Page, 2004: 5) which links tourism-generating regions with the destinations and provides access within the destinations in a predominantly utilitarian way (Hall, 1999). Second, transport can also be the central component of the tourist experience: this is 'transport as tourism' (Lumsdon and Page, 2004: 5), which is the focus of the present paper. Here, the transport mode is pivotal to the tourist experience (Page, 2009) and 'the journey itself, as much as the destination, may be part or even the prime attraction of the trip' (Speakman, 2005: 129). In this form of tourism, the mode of transport becomes part of the core experience and can sometimes be its main determinant. For example, a cruise ship with its amenities and services can be central to the forming of the experience not necessarily the destinations on the itinerary (Hosany and Witham, 2009; Severt and Tasci, 2020). An increasing number of people taking these types of holidays by an immense range of transport modes (Dileep, 2019) suggests that more dedicated studies of the phenomenon are needed to ensure the body of research remains broadly representative of real world market developments. In order to reflect terms such as heritage tourism, sports tourism and other forms of special interest tourism, and to link 
transport more explicitly within the tourist experience, we suggest using the term transport tourism for discussing tourism where the mobility of particular modes of transport are central to the development of the tourist experience.

Mobility is meaningful and embodied, socio-culturally produced motion (Sheller and Urry, 2006; Cresswell, 2006) and a key element of the modern life (Urry, 2007). Mobilities theory (Sheller and Urry, 2006; Urry, 2007; Hannam, 2009; Sheller, 2014) allows us to pay attention to 'the experiential value of mobility [which means] investigating the individual and subjective components of transport, although still relating them to concrete asset of technical and technological transport settings' (Scuttari, 2019: 19). Therefore, it is a useful concept for theorising the transport tourist experience, which happens 'on the move' (Cresswell, 2006), following a route where 'the "places" are steps or stages along the way' and the travelling process is more important than reaching a particular destination (WardPerkins et al., 2020: 2).

'Tourism mobilities involve complex combinations of movement and stillness, realities and fantasies, play and work' (Sheller and Urry, 2004: 1) and transport tourism includes a wide variety of difference in terms of motive force, skill level, tempo, transport mode or level of tourist engagement. Mobile tourist endeavours as different as ocean cruises (Hosany and Witham, 2009; Huang and Hsu, 2010; Di Vaio et al., 2018), sailing, boating, kayaking and canoeing on inland and maritime waters (Hall and Härkönen, 2006; Mullins, 2009; Rhoden and Kaaristo, 2020), coach tours (Edensor and Holloway, 2008; Larsen and Meged, 2013), cycling and motorcycling holidays (Scuttari, 2019), train travel (Jensen et al., 2015) and many more account for millions of holidays each year. These holidays feature a wide variety of organisational forms spanning from fully inclusive package holidays to almost entirely independent travel (Lumsdon and Page, 2004). The focus of the abovementioned research, however, has mostly been on tourist experiences and motivations associated specifically with their particular modes of transport. Studies focusing on the experience of mobility as a key part of the tourist experience across different transport modes have been rarer until recently (Page, 2009; Scuttari, 2019).

Despite their vast modal differences, mobility is central to experiences in all of the above-listed forms of transport tourism, even if it not theorised through this particular 
concept. The present study therefore contributes to the development of the notion of transport tourism, which we understand as a mode of recreational activity where mobility is the central part of tourism product and experience and can therefore be considered a tourist attraction in and of itself.

\section{Glancing at everyday landscapes of tourism}

When engaging in transport tourism, tourists consume the mobility of the vehicle or vessel moving in and through the surrounding landscapes, which we understand as a 'set of relationships between places in which meaning is grounded in existential consciousness, event, history and association' (Tilley and Cameron-Daum, 2017: 2). However, it should be highlighted that landscapes are not just representational and metaphorical since they also form 'through concrete production and consumption processes that connect people to the world by contextualizing their experiences' (Saraniemi and Kylänen, 2011: 138). Looking outwards from the 'tourist bubble' (Jaakson 2004) it is evident that the mobile tourist landscapes are also material, embodied and sensory (Edensor, 2006; Scuttari, 2019).

Urry (1990, 2002), and subsequently Urry and Larsen (2011), have provided a seminal critical framework for analysing the tourist perception and consumption of the surroundings through the predominantly visual sense, the tourist gaze. This is simultaneously ideological and experiential and 'at least part of the [tourist] experience is to gaze upon or view a set of different scenes, of landscapes or townscapes which are out of the ordinary' (Urry, 2002: 1). The spectatorial gaze that 'involves the collective glancing at and collecting of different signs that have been very briefly seen in passing at a glance such as from a tourist bus window' (Urry, 1995: 191) is especially relevant in this context and has been further developed by Larsen (2001) through the notion of travel glance. The latter is a mobile, cinematic way of experiencing the environment which is co-produced by the means of transport: trains and cars become 'vision machines' (Larsen, 2001: 88), mediating the visual consumption of the surroundings from the moving vehicles, sealed environments travelling at relatively fast speed. The tourist glance is therefore somewhat detached and passive, and forms largely in terms of isolation and distance from that which is glanced 
upon. Indeed its focus on 'speed, mobile visual perception, bodily immobility, and the promise of a pleasurable touristic journey' (Larsen, 2001: 94) might be argued to be the defining characteristics of a wide range of passive transport tourism products.

However, assuming no sensory impairment and in terms of the lived experience of the environment, visual consumption of the surroundings is always accompanied by other senses: sounds (or the perceived lack of), smells, tastes or haptic sensations (Edensor, 2006). In fact, 'in almost all situations different senses are inter-connected with each other to produce a sensed environment of people and objects distributed across time and space' (Urry 2002: 146). Participants in a coach tour for instance consume the surroundings visually, while listening to the tour guide, sensing the comfort (or discomfort) of the seat, sensing the smells in and outside of the coach, while consuming snacks and drinks (Edensor and Holloway, 2008). There are complicated sensory interplays at work when the tourist interacts with the surrounding world (Edensor, 2006; Jensen et al., 2015). As Scarles (2009: 466) argues, 'visuals and visual practice are not mere aides in the tourist experience, but emerge through fluid interplays that light up the process of becoming by instilling life and mobilising deeper affiliations between self and other.' We therefore suggest it is better to conceptualise the tourist experience of mobility as a conglomerate of various representational and non-representational elements, whereby the tourist experience is a co-creation of the simultaneously sensory and cognitive interactions between the tourists and their environment.

The travel glance (Larsen, 2001) nevertheless provides a valuable theoretical explanation on the construction of the tourist experience via mobility. Through this theoretical lens, we can follow how transport tourism affords specific ways of both engaging with the (travel) surroundings, and of co-creating mobile landscapes. The objects and subjects of the tourist gaze and glance can be varied and do not represent only preconceptions of cultures and places constructed by the tourism industry and media. the tourist views more than just what ought to be seen as dictated by the tourism industry: 'as tourists move through place, collective discourses merge with subjective experiential encounters that unfold as not only prescribed and anticipated but also immanent and personalised' (Scarles, 2009: 479). Hence, tourists are co-creators of the tourist gaze and glance. Furthermore, as has been increasingly demonstrated in the recent tourism literature 
(McCabe, 2002; Edensor, 2007; Larsen, 2008; Maitland, 2010; Kaaristo and Rhoden, 2017; Isabelle et al., 2019), tourists do not only look for and consume extraordinary sights and experiences, but also the ordinary and the everyday: that 'heroic realm of modernity, full of creativity, manipulation and resistance' (Larsen, 2008: 23). This has important implications for the understanding of both the tourist motivation and experience:

For some visitors, an important element in the appeal of the city is the opportunity to experience and feel a part of everyday life. These visitors do not seek recognized tourist attractions or tourist precincts but what they perceive as the real life of the city - a place in which overlapping activities of tourism and leisure now form part of its fabric and life. For them, the everyday and mundane activities of city residents take on significance as markers of the real, and off the beaten track areas, not planned for tourism, are valued as offering distinctiveness (Maitland 2010: 176).

Tourism mobilities are imagined and sensed, visual and embodied, utilitarian and festive, extraordinary and mundane. Recognising the key elements of how the tourists interact with and co-create the landscapes in movement is therefore of key importance in understanding the transport tourism experience. The travel glance therefore needs further study in terms of differing transport modes, as one of the key elements of mediating, facilitating and shaping the mobile tourist experiences of places with multiple and sometimes contested meanings.

\section{Study methods}

This study is interpretive and qualitative, with the aim of gathering data pertaining to cruise and coach tourists' experiences of travelling by their chosen mode of transport tourism (cruise or coach), together with the key focus on the topics that research participants found most important. Qualitative data was collected using semi-structured in-depth interviews with coach and cruise tourists. To ensure that the interviews covered the pertinent topics and work towards procedural reliability, the interview guide used was developed from the literature review. It consisted of the following three sections: 1) reasons for choosing the particular type of holiday (including details such as where, with whom, when, how long, and the purchasing specifics); 2) experiences of the holiday (descriptions of a typical day, feelings about constant movement during the holiday, various activities undertaken, 
sensory experiences (views, smells, sounds, tactile sensations, tastes) on the moving vehicle or vessel; 3) personal details. The interview guide was semi-structured to provide the research participants with the necessary flexibility to disclose and introduce new data and topics.

Interviewees were identified through theoretical sampling (Glaser and Strauss, 2017), a cumulative method that is based on the category saturation and allows for the researchers to identify the interviewees 'according to their (expected) level of new insights ... in relation to the state of elaboration so far' (Flick, 2009: 118). During the data collection, interviews alternated between cruise and coach tour interviewees and each interview lasted approximately 1 hour on average. In line with theoretical sampling recommendations (Glaser and Strauss, 2017), data collection continued as long as the selected interviewees continue to yield themes that contributes towards theory generation and therefore this method necessitates parallel data collection and analysis. Theoretical saturation occurs when the emergence of new themes ceases and, at this point data, collection stops. In the present study, theoretical saturation was determined at 12 interviews and was evidenced through the stability of the thematic codebook. This number is in keeping with the findings of Guest et al. (2006) who show that 12 interviews are sufficient to establish a detailed codebook while six interviews are sufficient to discover less detailed, overarching themes.

All the interviewees were white, middle-class British citizens, where half had been on coach tours and half on cruises. Both genders were interviewed (three females and three males for both coach tours and cruises). All of the coach tourists were over 35 years old, including three who were over 60 years old. Two of the cruise tourists were younger than 35 years old, two were aged between 35 and 60 years, and two were over 60 years old. Apart from the retired interviewees (two coach and one cruise tourist), all were employed during the time of the interview. The discussions focused on their international package holidays (coach: Hungary, Germany, Australia, Austria, Italy, Jordan, China, India, Peru, and USA; cruise: Mediterranean, Caribbean, Baltic, Grand Canal in China, Panama Canal and Alaskan coastline). To preserve anonymity, the interviewees were coded according to the type of holiday in which they had participated (cruise $=\mathrm{Cr}$; $\operatorname{coach}=\mathrm{Co}$ ), their gender (male=M; female=F) and are differentiated by a cardinal number. 
The interviews were transcribed and coded using NVivo 12 data management software. Data was analysed using thematic analysis, an inductive process of data reduction from interview transcripts to a codebook of themes (Flick, 2009). The initial codes attributed to sections of data, that were later classified categories of description, arose from the primary data and not from the literature review. These themes were then analysed, and links between themes were induced. Similarities and differences between experiences according to whether the interviewee had participated in a coach or cruise holiday were explored where appropriate.

\section{Results: Experiencing the travelling landscapes}

All the interviewed tourists referred to their transport tourism experience as 'mainly visual ... Travelling in a coach, the movement in the vehicle is like a cinema: you're watching things go past' (Co-M1). Two key elements as experienced within the collective transport tourism experience, reported below, emerge in our analysis: the importance of the constant variability of the changing scenery that emerges in mobility and the subsequent opportunity to observe the everyday life from these moving vehicles.

\subsection{Mobile landscapes: the changing scenery}

Without exception, all of the interviewees reported that the most enjoyable part of travelling for them was the feeling of novelty, described as 'experiencing something new' $(\mathrm{Cr}-\mathrm{M} 2)$. By this, the transport tourists do not simply mean the difference between going on holiday to a destination outside of their everyday environment but that constant mobility of the coach or ship gives them an opportunity to experience 'lots of something new' (Co-F1). A research participant explained why he preferred coach tours to travelling to a destination and staying there for a period of time: 'If you're going to go on a holiday and you're going abroad, and you're going to see the world, you've got to move around' (Co-M3), thus linking mobility and visuality of the tourist experience. Viewing the surrounding scenery predominates in the experiences of the tourists: 'My eyes are open all the time, looking out 
and enjoying the scenery wherever I am' (Co-F2). The mode of transport and having to assume no control of the vehicle plays a key role in the experience formation: 'You had the advantage on the coach of being able to look out the window when you're travelling and look at the scenery far more than you would if you were a driver in a car' (Co-M1).

On a cruise ship, views of surrounding scenery are similarly central to the experience: 'Most of it [the cruise to Alaska], you see land. You've got land either side and you've either got a glacier and you're looking at bears, not polar bears, ordinary black bears and things like that. That's why I liked it' ( $\mathrm{Cr}-\mathrm{F} 3)$. These statements coincide with the experiences of coach tourists and therefore demonstrate the centrality of the landscape to the experience of travel. Indeed, an interviewee even states how she would not participate in a cruise that involved extensive sea travel without the possibility of the sight of landscapes:

I don't say l'd cruise on the Med[iterranean] or the Caribbean because I like to see land. I think if you go to Barbados or the Med, you don't see scenery for days. All you can see is sea, isn't it? But I would go on a Norwegian cruise because that, I would imagine, would be similar [to the Alaskan cruise] because you'd have the fjords so you can go up on deck on the ship and look out and have all this beautiful scenery for miles ( $\mathrm{Cr}-\mathrm{F} 3)$.

Not being able to see landscapes was considered undesirable to cruise tourists: 'Basically you don't stop, you don't get to get off the ship, you're just on 24/7. I'm sure we had just short of a week, something like five or six days, where we were just at sea all day' (Cr-F1). However, that is not to say that the sea offered no new experiences: 'We like to sit on the balcony and look for wildlife in the sea. There's flying fish and dolphins and no matter how far out in the Atlantic you are, there's always a bird' ( $\mathrm{Cr}-\mathrm{F} 2)$. In these accounts, certain patterns in the cruise tourists' experiences becomes apparent. Port days are mentioned as enjoyable, since in addition to the prospect of visiting the port destination, port days necessitated travel relatively close to the shoreline and thus enabled the viewing of landscapes whilst travelling.

It is important to note that it is more than simply the presence or a view of a landscape that proves attractive for the transport tourists, but rather the fact that the views are continuously changing due to the movement of the vessel or vehicle: 
There was always something to watch out for, the scenery changes. A lot of people just sit up on deck and watch it and see the change (Cr-F3).

You can take in not only the place you're going but also the scenery as you move from place to place. I will be looking at the scenery at the side... you know, the scenery moves past me. The routes, for me, are just as interesting as the destinations (Co-F1).

However, this means that travelling by coach or close to land on the cruise ship, both of which facilitate visual consumption of the surroundings, does not necessarily equate with an enjoyable experience because instances of limited variation in landscapes is attributed less value: 'Sometimes you were on a motorway so you didn't see things then' (Co-F3). The tour guide can also mediate this notion: 'on these long roads where there's nothing to see the courier will say sometimes there's nothing on this road for another hour' (Co-M3). Equally, 'going through the Panama Canal is not as interesting as going alongside countries [in the Mediterranean] because it was just mostly trees, so other than that there wasn't really anything else to see' ( $\mathrm{Cr}-\mathrm{F} 1)$. However, for this particular interviewee, it was still 'better going through the Panama Canal than the lead up to it when there was just sea' ( $\mathrm{Cr}-\mathrm{F} 1)$. There would therefore appear to be a certain hierarchy of visuals that transport tourists consume, based on a gradation of increasing enjoyment that arises from views that are perceived as unchanging, such as the sea alone (lower enjoyment), landscapes that are relatively unvarying (higher levels of enjoyment), and landscapes that offer continuously changing views (highest levels of enjoyment).

In addition to these value and preference based judgements, any particular view also depends on the physical and bodily positioning of the viewer on board of the vehicle or vessel. All the interviewed coach tourists explained how the operators that they had travelled with had some form of seat rotation system that prevented the tourists being seated in any one place for the duration of the tour. These seat rotation systems become important in the development of the experience since they ensure that the coach tourists' continuously changing views of landscapes do not emerge only due to an ever-changing view as the coach travels along its route, but also because of a change in their vantage point resulting from differing placement within the coach itself. These changes can improve or worsen the particular experience. The following coach tourist describes how at one point 
during her holidays she and her husband had their turn to be seated in the front seat, a much-coveted spot for most of her fellow holidaymakers, but not for her:

Everybody always says they want the front seat, but I never want the front seat so I try to forego it if I can. Why? Because I will just drive then! [Laughs] I won't be able to take my eyes off the road. I'll tell him [the driver] to slow down. I'll make him as nervous as I make my husband! If I'm at the front, all I will do is look at the road [and] in a sense, I will be driving. I don't want the reality of looking at the road and worrying. The thing is, I don't like travelling on motorways. That's the ironic thing, on the coaches you do travel on a lot of motorways. But maybe you don't feel responsible; you feel safe in some silly way (Co-F1).

The transport mode effectively guides the mobile experience, as the delegation of driving responsibility to the operator does not only mean that tourists can engage in visually consuming landscapes, but that they can do so in perceived safety. This creates a certain juxtaposition of activeness and passiveness: the tourists do not want to assume any responsibility, or even a feeling of responsibility, and the need for novelty and variation is directed towards the constantly changing landscapes outside.

\subsection{Touristic landscapes of the everyday}

An important element of the transport tourists' narrations of their visual consumption of the surroundings is their interest in human activity. Views of the everyday life of the host population play an important part of the experience of coach tourists because it is these views, rather than the country's iconic sights, that provide a discernible experience:

You just look at lots and lots of little things. There's the occasional major thing, 'Oh, look over there! There's the Eiffel Tower.' But the majority of things are, 'Oh, look there. There's a man on a scooter with a dog stood up between his legs.' That's what I remember far more than the major things (Co-M1).

Go up the Grand Canal, there's families and they're doing their washing and eating, and paddling in the water ( $\mathrm{Cr}-\mathrm{M} 3$ ).

Consuming snapshots of the locals' everyday life - in the following example observing a woman in her house - is something that the tourists feel comfortable doing from the detached space of the coach. Had this coach tour participant been on foot, 
I would have felt awkward seeing that lady. I couldn't have walked up to her and said hello. I would have been intruding on her life. But it was nice to see these little snapshots of what life, normal life, is like other than the tourist attractions (Co-F1).

The views that coach travel can afford do not necessarily have to be perceived by the tourist as picturesque. An interviewee recalled how, during her travels around New Orleans, USA, one year after the floods associated with Hurricane Katrina of 2005, she saw evidence of the damage that it had caused and was most affected by the mundane elements of the aftermath of the natural disaster she witnessed:

When you see the houses and it was nearly 12 months on, and nothing had been done. They just had all this blue sheeting on the roofs and she [the tour guide] told us that the blue sheet on the roof means the house has got to be demolished. Then you go a bit further and there were massive caravan parks that they'd [the residents] been put in. So they'd been used to, say, a fourbedroom house or whatever, and they [the authorities] just put them in these little caravan-trailers and they'd been in there ages... Yeah [pauses], going into New Orleans it was a bit upsetting because I thought, 'We're here coming on holiday enjoying ourselves and these people, they've been left with nothing.' So I felt a bit sorry for a lot of them (Co-F3).

Glancing at the potentially upsetting views also allows tourists to reflect on the meaning, impact and the moral aspects of what they are doing. In this instance, the coach 'bubble' serves to distance the viewer from the viewed to the degree that the host communities are exoticised so much as to be equalised with 'nature' and by casual association almost excluded from human society and therefore the viewer's responsibility:

It makes you think there is a huge divide in the world, in poverty, and the way that people live, and the way they accept life. Over in India there are some very rich people as well, it's not all like that [poor]. But wherever you go, particularly in the Middle East and the Far East, the poverty is unbelievable, and South America is the same. You've got to really say to yourself, 'I'm only here for a short time; I'm a witness to it, I can't get involved.' So yes, the cultural part is seeing how people live; there's nothing you can do about it. It's like watching, for instance, a lion take a deer; it's part of life. You know that is nature, and you can't affect nature (Co-M2).

Cruise tourists talked less about viewing domestic everyday life scenes of the host population whilst travelling, since large cruise ships mostly cannot travel close enough to land to afford such views. Nevertheless, that is not to say that the cruise experience contains no mobile views of everyday life as a tourist attraction. The cruise tourists' views 
often tended to be of the industrial activity related to shipping rather than the home and street life as seen by coach tourists. In addition to the natural attractions of sea life, cruises allow for plenty of views of shipping activities:

Ships, ferries, yachts, fishing trawlers. I would quite happily go and sit on, or walk around, the promenade deck and look and spend the time doing it. And I think the fact that I've got endless photos of ships that we passed perhaps is testimony to it! (Cr-M1)

Just spend time in the harbour watching the yachts going in and out, and just soaking up the atmosphere ( $\mathrm{Cr}-\mathrm{M} 3)$.

Equally, arrival at and departure from ports proved enjoyable because of the specific shipping activities associated with docking: 'They have, like, a pilot for that port [who] comes with his little boat, and he gets on and he takes over the ship to get into the harbour. So it was quite interesting to watch, yeah' (Cr-F1).

The mobile experience of cruises and coach tours is more than the sum of the destinations visited: it is the visual experience of mobility on a particular mode of transport that adds to the enjoyment of these holidays. Mobility means that tourists are constantly exposed to new things, and the route is a key source of new stimuli. The continuously changing surroundings allow tourists to repeatedly see something new. The landscapes (the more varied the better) through or near to which the vehicle or vessel travels, as well as views of human everyday life within these environments, are enjoyed. Views of human activities are considered mind expanding, particularly when the views are of everyday life in places en route, even when they might be upsetting. However, there are also times when views of the route are perceived with relative indifference and its importance in the tourist experience fades. These situations occur when the route is largely unvaried and opportunities for exposure to something new are limited. 


\section{Discussion and conclusion: co-creating the changing landscapes of everyday life in tourism}

The dominance of visual engagement with the surroundings in the narratives of the tourists presented above supports Urry's (1990; 2002) argument that tourism centres largely upon gazing the surrounding environs. The fleeting and varying visual involvement tourists have with their surroundings whilst 'on the move' (Cresswell, 2006), the travel glance (Larsen, 2001 ) is an important way of consuming but also co-producing the tourist landscapes. The focus on the visual dimension of the experience, however, does not mean an assumption of no or little involvement of other senses (Scarles, 2009). On the contrary, the body of work by tourism scholars written in direct response to Urry's thesis (e.g. Veijola and Jokinen, 1994) as well as by Urry himself (Urry and Larsen, 2011) demonstrates the multi-sensoriality of the experience. The tourist glance is not a passive act: as we demonstrated, glancing is in fact active, and includes the bodily choreography of movements on board of the vehicle, necessary for acquiring the best bodily position for executing the glance.

The interviewed tourists happily transferred most of the responsibility to the tour guides, to the point that one interviewee did not even want to sit in the front seat. Urry and Larsen (2011: 114) conceptualise this kind of behaviour as almost child-like whereby 'one is told where to go, how long to go for, when one can eat, how long one has to visit the toilet and so on' but with the full understanding by the tourists that they are also 'playing at being a tourist.' This allows us to conceptualise coach tours and cruises as passive transport tourism, chosen primarily because of the enjoyment associated with travel itself, where the operator plans the route and the tourists are not responsible for driving the vehicles or vessels. This frees time to engage more with the landscapes through which the vehicle is travelling, leading to happiness, excitement, relaxation and calm as the passive transport tourist is able to focus their full attention on the views, mobility, socialising as well as the supporting products.

The amenities of the particular mode of transport can be more important to the development of the tourist experience than the specific destinations (Hosany and Witham, 2009; Severt and Tasci, 2020). However, as our findings demonstrate, mobility - movement of the cruise ship or coach and the subsequent variability of the visual experience - is also a 
significant part of the development of the experience. Mobility affords landscape views with maximum variability, which were most popular for both coach and cruise tours, thus confirming findings by Schirpke, Tasser and Tappeiner (2013) that assessment of scenic beauty is in positive correlation with the complexity, diversity and variedness of landscape, whereas large homogeneous areas are perceived as less beautiful. However, our study also found that in addition to the varied landscape views (Alexiou, 2018) the transport tourists are also interested in the views of everyday life sometimes seen as different or unexpected compared to the tourists' habitual home environment (Ory and Mokhtarian, 2005). Gazing upon the perceived 'otherness', and particularly the opportunity to observe familiar practices in a novel context, is one of the important elements of the tourist gaze (Urry, $1990 ; 2002)$. In glancing at the everyday lives of the destination communities, the tourists fulfil their need to go beyond the traditional tourist enclaves (Edensor, 2001). They ascribe value on the views of the mundane activities of the local residents of the visited place, 'constructing their own narratives and relishing everyday scenes - which can seem more extraordinary than a spectacular icon obviously planned for tourist consumption or a heritage building already familiar from countless media images' (Maitland, 2010: 183). This applies even if what they glance at is somewhat upsetting and can be explained as the tourists' desire for what they conceive as reality and authenticity as well as their need 'to perceive oneself as a brave and serious traveller in contrast to a foolish and superficial tourist' (Meschkank, 2011: 53).

Mobility, the constant movement of the vehicle or vessel, allows tourists to direct their gaze and glance or withdraw it altogether (cf. Larsen and Meged, 2013). This does result in the visual experience of landscapes likened to a cinematic experience, supporting the suggestion of touristic vehicles as 'vision machines' (Larsen, 2001: 88). In the case of the coach tourists, the cinematic nature of the experience is also a product of their relatively fast-moving travel through landscapes (Larsen, 2001; Edensor and Holloway, 2008). Indeed, the coach tourists reflected upon this aspect of their holidays, unprompted, using words like 'cinema', 'film' and 'movies' in the interviews. However, rather than simply gazing upon sights at tourist destinations, the travelling landscapes the tourists move through are cocreated (Scarles, 2009) through collaboration between the tourist, mode of mobility and the route. As we have demonstrated, the mode-related dimension includes the experiences 
gained through, and related to, the engagement with the particular vehicle or vessel. Routerelated experiences are associated with the environments through which the mode of transport travels, and include rural and wild landscapes, seascapes, and cityscapes, whereby it is the progression along the route, that is, mobility, that makes them significant for the tourists (Mullins, 2009). The travelling landscapes therefore are a result of the visual mobile transport tourist experiences that form in the intersection of the tourist glancing at the surroundings and everyday life of the local residents.

Although our focus on coach and cruise holidays has allowed analysis of the visual aspect of the passive transport tourist experience, it has limitations associated with its sampling method. Coach and cruise are but two of a range of passive transport tourist experience types and thus further research could explore whether the themes arising in this work are replicated more broadly. The sample size was relatively small and, although data saturation was achieved, future research could test the findings more broadly. Nevertheless, our research offers suggestions for practical application to coach and cruise operators. The tourists' desire to view constantly changing landscapes indicates that route design is important to enhance holiday satisfaction. Route-design is ultimately a trade-off between utility (time and price, predominantly) and the aesthetic concerns of the travelling landscape, where practicable route design should allow maximum variety, including both the picturesque in nature and views of everyday life (residential and commercial/industrial).

As well as the practical implications, we propose several avenues for future research. The visual is but one component of the experience of mobility and therefore future studies could research other aspects of the mobile tourist experience, such as sociality, the relationship with other tourists. Equally, more active transport tourism activities, those in which the tourists drive or navigate the transport mode (such as sailing, cycling or car holidays), are ripe for study to broaden our analysis further. This could subsequently provide a holistic analysis of tourists' experiences of various transport modes, which would enable a further development of an experiential model of transport tourism. 


\section{REFERENCES}

Alexiou, M. V. (2018), "Modeling guided tour participants' experiences", International Journal of Culture, Tourism and Hospitality Research, Vol. 12 No. 3, pp. 257-276.

Cresswell, T. (2006), On the move: mobility in the modern Western world. New York: Routledge.

Di Vaio, A., Lepore, L. and Varriale, L. (2018), "Self-organised cruiser's expenditures in a port of call: the interaction effect between city interface satisfaction and super-sized ships", International Journal of Culture, Tourism and Hospitality Research, Vol. 12 No. 4, pp. 385406.

Diana, M. (2008), “Making the 'primary utility of travel' concept operational: A measurement model for the assessment of the intrinsic utility of reported trips", Transportation Research Part A: Policy and Practice, Vol. 42 No. 3, pp. 455-474.

Dickinson, J. E. and Robbins, D. (2008), "Representations of tourism transport problems in a rural destination", Tourism Management, Vol. 29 No. 6, pp. 1110-1121.

Dileep, M. R. (2019), Tourism, transport and travel management. New York: Routledge.

Dodds, R. (2019), "The tourist experience life cycle: a perspective article", Tourism Review, Vol. 75 No. 1, pp. 216-220.

Edensor, T. (2001), "Performing tourism, staging tourism: (Re)producing tourist space and practice”, Tourist Studies, Vol. 1 No. 1, pp. 59-81.

Edensor, T. (2006), "Sensing tourist spaces", in Minca, C. and Oaks, T. (eds.) Travels in paradox: Remapping tourism. Lanham: Rowman and Littlefield, pp. 23-46.

Edensor, T. (2007), "Mundane mobilities, performances and spaces of tourism”, Social \& Cultural Geography, Vol. 8 No. 2, pp. 199-215.

Edensor, T. and Holloway, J. (2008), "Rhythmanalysing the coach tour: The Ring of Kerry, Ireland", Transactions of the Institute of British Geographers, Vol. 33 No. 4, pp. 483-501.

Ellis, G. D., Freeman, P. A., Jamal, T. and Jiang, J. (2017), "A theory of structured experience", Annals of Leisure Research, Vol. 22 No. 1, pp. 97-118.

Flick, U. (2009), An Introduction to qualitative research. London: Sage.

Glaser, B. G., and Strauss, A. L. (2017), "Theoretical sampling”, in Denzin, N. K. (ed.) Sociological methods. A Sourcebook. London: Routledge, pp. 105-114.

Guest, G., Bunce, A., and Johnson, L. (2006), "How many interviews are enough? An experiment with data saturation and variability", Field Methods, Vol. 18 No. 1, pp. 59-82

Hall, C. M. and Härkönen, T. (2006), Lake tourism: An integrated approach to lacustrine tourism systems. Bristol: Channel View Publications. 
Hall, D. R. (1999), "Conceptualising tourism transport: inequality and externality issues", Journal of Transport Geography, Vo. 7 No. 3, pp. 181-188.

Hannam, K. (2009), "The end of tourism? Nomadology and the mobilities paradigm", in Tribe, J. (ed.) Philosophical issues in tourism. Bristol: Channel View Publications, pp. 55-70.

Hosany, S., \& Witham, M. (2009). “Dimensions of Cruisers' Experiences, Satisfaction, and Intention to Recommend", Journal of Travel Research, Vol. 49 No. 3, pp. 351-364

Huang, J. and Hsu, C. H. C. (2010), "The impact of customer-to-customer interaction on cruise experience and vacation satisfaction", Journal of Travel Research, Vol. 49 No. 1, pp. 79-92.

Isabelle, F., Dominique, K., and Statia, E. (2019), "Home away from home: A longitudinal study of the holiday appropriation process", Tourism Management, Vol. 71, pp. 327-336.

Jaakson, R. (2004), "Beyond the tourist bubble? Cruiseship passengers in port", Annals of Tourism Research, Vol. 31 No. 1, pp. 44-60.

Jensen, M. T., Scarles, C., and Cohen, S. A. (2015), "A multisensory phenomenology of interrail mobilities", Annals of Tourism Research, Vol. 53, pp. 61-76.

Kaaristo, M. and Rhoden, S. (2017), "Everyday life and water tourism mobilities: mundane aspects of canal travel", Tourism Geographies, Vol. 19 No. 1, pp. 78-95.

Larsen, J. (2001), "Tourism mobilities and the travel glance: Experiences of being on the move", Scandinavian Journal of Hospitality and Tourism, Vol. 1 No. 2, pp. 80-98.

Larsen, J. (2008), "De-exoticizing tourist travel: Everyday Life and Sociality on the Move", Leisure Studies, Vol. 27 No. 1, pp. 21-34.

Larsen, J., and Meged, J. W. (2013), "Tourists co-producing guided tours", Scandinavian Journal of Hospitality and Tourism, Vol. 13 No. 2, pp. 88-102.

Lumsdon, L. M. (2000), "Transport and tourism: cycle tourism - a model for sustainable development?", Journal of Sustainable Tourism, Vol. 8 No. 5, pp. 361-377.

Lumsdon, L. M. and Page, S. (2004), Tourism and transport: Issues and agenda for the new millennium. London: Elsevier.

Maitland, R. (2010), "Everyday life as a creative experience in cities", International Journal of Culture, Tourism and Hospitality Research, Vol. 4 No. 3, pp. 176-185.

McCabe, S. (2002), "The tourist experience and everyday life", in Dann, G. (ed.) The tourist as a metaphor of the social world. Wallingford: CABI, pp. 61-77.

Meschkank, J. (2011), "Investigations into slum tourism in Mumbai: poverty tourism and the tensions between different constructions of reality", GeoJournal, Vol. 76 No. 1, pp. 47-62. 
Metz, D. (2004), "Travel time constraints in transport policy", Proceedings of the Institution of Civil Engineers - Transport, Vol. 157 No. 2, pp. 99-105

Mullins, P. M. (2009), "Living Stories of the Landscape: Perception of Place through Canoeing in Canada's North", Tourism Geographies, Vol. 11 No. 2, 233-255.

Ory, D. T. and Mokhtarian, P. L. (2005), "When is getting there half the fun? Modeling the liking for travel", Transportation Research Part A: Policy and Practice, Vol. 39 No. 2-3, pp. 97-123.

Page, S. (2009), Transport and tourism: Global perspectives. Harlow: Prentice Hall.

Page, S. and Connell, J. (2014), "Transport and Tourism", in Lew, A. A., Hall, M. C. and Williams, A. M. (eds.) The Wiley Blackwell Companion to Tourism. Oxford: Wiley Blackwell, pp. 155-167.

Quan, S. and Wang, N. (2004), "Towards a structural model of the tourist experience: An illustration from food experiences in tourism", Tourism Management, Vol. 25 No. 3, pp. 297305.

Rhoden, S., \& Kaaristo, M. (2020), "Liquidness: Conceptualising water within boating tourism”, Annals of Tourism Research, Vol. 81, 102854.

Ryan, C. (2010), "Ways of conceptualising the tourist experience - A review of literature", Tourism Recreation Research, Vol. 35 No. 1, pp. 37-46.

Saraniemi, S., \& Kylänen, M. (2011), "Problematizing the Concept of Tourism Destination: An Analysis of Different Theoretical Approaches", Journal of Travel Research, Vol. 50 No. 2, pp. 133-143.

Scarles, C. (2009), "Becoming tourist: Renegotiating the visual in the tourist experience", Environment and Planning D: Society and Space, Vol. 27 No. 3, pp. 465-488.

Schirpke, U., Tasser, E., and Tappeiner, U. (2013), "Predicting scenic beauty of mountain regions", Landscape and Urban Planning, Vol. 111, pp. 1-12

Scuttari, A. (2019), Cycling and Motorcycling Tourism: An Analysis of Physical, Sensory, Social and Emotional Features of Journey Experiences. Cham: Springer.

Severt, D. E., and Tasci, A. D. (2020), "Cruising back to the basic needs", International Journal of Culture, Tourism and Hospitality Research, Vol. 14 No. 2, pp. 173-187.

Sharples, L. (2019), "Research note: customer experience management in cruise preconsumption", International Journal of Culture, Tourism and Hospitality Research, Vol. 13 No. 2, pp. 235-243.

Sheller, M. (2014), "The new mobilities paradigm for a live sociology", Current Sociology, Vol. 62 No. 6, pp. 789-811. 
Sheller, M., and Urry, J. (2004), Tourism mobilities: Places to play, places in play. London: Routledge.

Sheller, M. and Urry, J. (2006), "The new mobilities paradigm", Environment and Planning A, Vol. 38 No. 2, pp. 207-226.

Smith, A., Robbins, D., and Dickinson, J. E. (2019), "Defining sustainable transport in rural tourism: experiences from the New Forest", Journal of Sustainable Tourism, Vol. 27 No. 2, pp. 258-275.

Speakman, C. (2005), "Tourism and transport: Future prospects", Tourism and Hospitality Planning \& Development, Vol. 2 No. 2, pp. 129-135.

Tilley, C. and Cameron-Daum, K. (2017), An Anthropology of Landscape. London: UCL Press. Tucker, H. (2007), “Performing a young people's package tour of New Zealand: Negotiating appropriate performances of place”, Tourism Geographies, Vol. 9 No. 2, pp. 139-159.

Urry, J. (1990), The tourist gaze. London: Sage.

Urry, J. (1995), Consuming Places. London: Routledge.

Urry, J. (2002), The tourist gaze. 2nd ed. London: Sage.

Urry, J. (2007), Mobilities. Cambridge: Polity Press.

Urry, J. and Larsen, J (2011), The tourist gaze 3.0. London: Sage.

Veijola, S. and Jokinen, E. (1994), "The Body in Tourism", Theory, Culture \& Society, Vol. 11 No. 3, pp. 125-151.

Volo, S. (2013), “Conceptualizing experience: A tourist based approach”, in Scott, N., Laws, E. \& Boksberger, P. (eds.) Marketing of tourism experiences. London: Routledge, pp. 19-34.

Ward-Perkins, D., Beckmann, C., and Ellis, J. (2020), Tourism Routes and Trails. Theory and Practice. Wallingford: $\mathrm{CABI}$ 